\title{
A More Precise Living Planet Index (LPI)
}

\author{
Katherine Hébert ${ }^{\ddagger}$ \\ ‡ Université de Sherbrooke, Sherbrooke, Canada
}

Corresponding author: Katherine Hébert (katherine.ahebert@gmail.com)

Received: 24 May 2019 | Published: 21 Jun 2019

Citation: Hébert K (2019) A More Precise Living Planet Index (LPI). Biodiversity Information Science and Standards 3: e36517. https://doi.org/10.3897/biss.3.36517

\begin{abstract}
Reliably measuring biodiversity change is of major interest both ecologically and politically. Thoroughly testing the reliability of biodiversity metrics, meaning their ability to present a precise, accurate, and unbiased measurement of biodiversity trends, is vital to avoid misinforming decision makers when selecting management strategies, and misleading the public's view of biodiversity issues.
\end{abstract}

Developed by Loh et al. (2005), the World Wildlife Fund (WWF), and the Zoological Society of London, the Living Planet Index (LPI) measures the overall global trend in vertebrate abundances since 1970 (Loh et al. 2005). The LPI has become a popular indicator of global biodiversity change due to its intuitive association with biodiversity targets, which makes it a powerful tool to communicate the status of biodiversity to the public, and to decision makers tasked with the management of biodiversity (Collen et al. 2009). Importantly, the Convention on Biological Diversity (CBD) selected the LPI as one of four indices approved to monitor progress towards the Aichi Biodiversity Targets (CBD 2016). The LPI was also selected as an Essential Biodiversity Variable, which are essential tools for the harmonized study, reporting, and management of biodiversity change worldwide (Pereira et al. 2013). Due to the LPI's pivotal role in policy, conservation, and communication, ensuring its reliability as a biodiversity change metric is crucial for both biodiversity science and management at a global scale.

Despite the LPI's influence on the global stage of biodiversity management, the index's reliability as a measure of biodiversity loss has not been rigorously tested for limitations. The LPI's capacity to accurately estimate global population trends depends in part on 
undetected errors in its supporting data, including process errors (i.e. random population fluctuations), and observation errors (i.e. poor detectability of certain species) (Clark and Bjørnstad 2004, Gotelli and Colwell 2001, Dennis et al. 2006, Buckland et al. 2004). These errors are often undocumented and cannot be directly assessed, making it difficult to determine their impact on LPI trends. Interpretation of an LPI trend also heavily relies on its precision, which establishes the uncertainty surrounding the estimated magnitude and direction of biodiversity change. If uncertainty is high, the LPI is a less reliable measure of biodiversity change, and must be interpreted with greater caution when communicating biodiversity trends to the public and when choosing management strategies (Hui et al. 2008). The LPI's confidence interval progressively widens as uncertainty accumulates over time from the baseline in 1970 (WWF 2018, McRae et al. 2017, Collen et al. 2009). This growing imprecision could impede our ability to confidently interpret both the direction and magnitude of biodiversity change, which has serious implications for monitoring progress towards global biodiversity targets, and for maintaining public engagement in biodiversity issues.

Here, we suggest a methodological approach to address this growing uncertainty, in order to improve the reliability of the LPI. We propose a methodology for integrating the covariation between population trends into the computation of the LPI, in order to bolster confidence in related trends and ultimately decrease imprecision. Rather than assuming all population trends are varying in isolation, we explicitly identify covariation between population trends, and weight populations according to this covariation. We then compare the confidence intervals of the reported LPI trend to the trend obtained using our proposed methodology, and consider the potential political, ecological, and communicational implications of this approach on the interpretation of biodiversity metrics.

\section{Keywords}

Living Planet Index, precision, biodiversity change, biodiversity metric

\section{Presenting author}

Katherine Hébert

\section{Presented at}

Biodiversity_Next 2019

\section{Hosting institution}

Université de Sherbrooke 


\section{References}

- $\quad$ Buckland ST, Newman KB, Thomas L, Koesters NB (2004) State-space models for the dynamics of wild animal populations. Ecological Modelling 171 (1-2): 157-175. https:// doi.org/10.1016/J.ECOLMODEL.2003.08.002

- $\quad$ CBD (2016) Indicators for the Strategic Plan for Biodiversity 2011-2020 and the Aichi Biodiversity Targets. In: UNEP (Ed.) Convention on Biological Diversity., XIII/28. Cancun, Mexico, 12 December 2016.

- Clark J, Bjørnstad O (2004) Population time series: Process variability, observation errors, missing values, lags, and hidden states. Ecology 85 (11): 3140-3150. https:// doi.org/10.1890/03-0520

- $\quad$ Collen B, Loh J, Whitmee S, McRae L, Amin R, Baillie JM (2009) Monitoring change in vertebrate abundance: the Living Planet Index. Conservation Biology 23 (2): 317-327. https://doi.org/10.1111/i.1523-1739.2008.01117.x

- Dennis B, Ponciano J, Lele S (2006) Estimation density dependence, process noise, and observation error. Ecological Monographs 76 (3): 323-341. https:// doi.org/10.1890/0012-9615(2006)76[323:EDDPNA]2.0.CO;2

- Gotelli N, Colwell R (2001) Quantifying biodiversity: procedures and pitfalls in the measurement and comparison of species richness. Ecology Letters 4 (4): 379-391. https:// doi.org/10.1046/j.1461-0248.2001.00230.x

- Hui D, Biggs R, Scholes R, Jackson R (2008) Measuring uncertainty in estimates of biodiversity loss: The example of biodiversity intactness variance. Biological Conservation 141 (4): 1091-1094. https://doi.org/10.1016/j.biocon.2008.02.001

- $\quad$ Loh J, Green RE, Ricketts T, Lamoreux J, Jenkins M, Kapos V, Randers J (2005) The Living Planet Index: Using species population time series to track trends in biodiversity. Philosophical Transactions of the Royal Society B: Biological Sciences 360 (1454): 289-295. https://doi.org/10.1098/rstb.2004.1584

- $\quad$ McRae L, Deinet S, Freeman R (2017) The diversity-weighted living planet index: controlling for taxonomic bias in a global biodiversity indicator. PloS one 12 (1).

- Pereira HM, Ferrier S, Walters M, Geller GN, Jongman RHG, Scholes RJ, Bruford MW, Brummitt N, Butchart SHM, Cardoso AC (2013) Essential biodiversity variables. Science 339 (6117): 277-278. https://doi.org/10.1126/science.1229931

- $\quad$ WWF (2018) Living planet report 2018: Aiming higher. World Wildlife Fund. [ISBN 288085265X] 